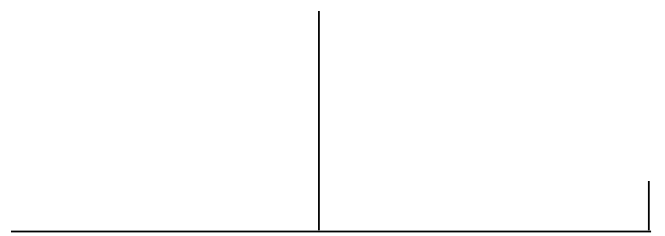

Rev. Latinoam. Psicopat. Fund., São Paulo, v. 13, n. 1, p. 53-70, março 2010

\title{
Reprodução assistida: os impasses do desejo*
}

Manuela Lanius

Edson Luis André de Souza

\begin{abstract}
A infertilidade é, para muitas mulheres, geradora de sofrimento psíquico, visto que a reprodução humana busca a perpetuação do ser. Este artigo faz uma discussão acerca das chamadas Novas Tecnologias Reprodutivas e estuda os efeitos que a infertilidade tem no psiquismo e na condição subjetiva dos sujeitos de desejo. Busca dissociar a demanda consciente de ter um filho do desejo inconsciente que opera na produção subjetiva, fazendo sintoma. Aponta a diferença entre o desejo de ter um filho e o desejo de maternidade e suas implicações na articulação das pulsões.
\end{abstract}

Palavras-chave: Infertilidade, reprodução humana assistida, feminilidade, desejo

* Artigo oriundo de pesquisa de Dissertação de Mestrado, defendida em 28/4/2008 no Programa de Pós-Graduação em Psicologia Social e Institucional da Universidade Federal do Rio Grande do Sul. 
Essa paixão pelo significante, por conseguinte, torna-se uma nova dimensão da condição humana, na medida em que não somente o homem fala, mas em que, no homem e através do homem, isso

fala, em que sua natureza torna-se tecida por efeitos onde se encontra a estrutura da linguagem em cuja matéria ele se transforma, e em que por isso ressoa nele, para além de tudo o que a psicologia das ideias pôde conceber, a relação da palavra.

(Jacques Lacan, 1958, p. 695).

Será que eu sou alguém capaz de procriar? Quem sou eu? Um homem ou uma mulher? Questões como estas fazem parte da construção subjetiva dos sujeitos de desejo, visto que, conforme Lacan, são questões endereçadas ao Outro, que retornam pela via de um reconhecimento simbólico.

Este estudo apontará alguns impasses do desejo expressos pela mulher infértil que busca, nas chamadas Novas Tecnologias de Reprodução Humana Assistida, um recurso para poder engravidar e ter seu filho consanguíneo. A partir deste campo situamos o significante infértil, este que agrega vários significados por sua característica polissêmica e mobiliza de modo singular cada sujeito que o inscreve em seu corpo, o qual entendemos como uma margem, uma fronteira entre o social 
e o sujeito. Situamos que a mulher que sofre com sua infertilidade, procura o médico como primeiro recurso, nos demonstrando que a implicação inicial do sujeito se dá para com seu corpo, na tentativa de que, ao curá-lo ou transformá-lo, o sujeito imagina que também possa transformar suas insígnias subjetivas.

Portando um sintoma que dá vistas no corpo, a mulher infértil encontra-se vinculada ao fenômeno que aparece em seu útero. Como seres de linguagem, estas mulheres expressam um desejo inconsciente que por vezes não condiz com a demanda consciente que dirigem à medicina - quero ter um filho. Encontramos nesta situação uma via de trabalho por meio da psicanálise que busca situar o lugar de desejo do sujeito do significante, circunscrever, por meio da escuta da enunciação do sujeito, o objeto causa de desejo. Neste sentido produz uma tensão à ciência biomédica que, pelo caminho inverso, produz objetos de desejo que podem funcionar como obturadores da falta.

Este é um tema de extrema atualidade e que ganhou uma certa presença na mídia depois que um autor da importância de Henri Atlan (2005) publicou em Paris o livro Útero artificial. Um ano antes, em 2004, uma importante jurista francesa e pesquisadora do CNRS, Marcela Lacub, havia publicado o livro Império do ventre - por uma história da maternidade. Neste livro discorre sobre uma série de casos que chegaram à justiça onde procura pensar as questões éticas que envolvem as tecnologias de reprodução, e o quanto estas endereçam perguntas importantes ao laço social contemporâneo. Marcela Lacub, inclusive, escreve um excelente artigo em um número especial da revista Le Nouvel Observateur (julho/agosto 2005), dedicado ao tema das utopias. Intitula seu artigo "A utopia do útero artificial". Enfatiza o quanto estas experiências nos permitem pensar novas formas de gerar vida, de confrontar o desejo dos sujeitos, mas que estas tecnologias, sobretudo, possam nos abrir verdadeiras experiências éticas dentro de um campo de liberdades e desejos, e não ser abafada por decisões muitas vezes vazias e preconceituosas da máquina jurídica. Aqui um campo de discussão se abre.

Não traremos a formulação de que a infertilidade tenha uma causa psicogênica, pois, deste modo, cairíamos na armadilha da dicotomia mente/corpo. Todavia, trabalharemos pelo viés lacaniano que aponta que o nascimento do sujeito se dá pelo esburacamento do real pelo significante, que se encarna no corpo e o molda, ou, dito de outro modo, de que entendemos que mente e corpo não estão dissociados quando escutamos o falasser.

Assim, não há como excluir o corpo da definição de sujeito do inconsciente. Sobre isto, Lacan trabalha reiteradas vezes em seu quinto seminário, "As formações do inconsciente", quando nos apresenta o Grafo do desejo. Ao 
analisarmos este grafo, vimos que temos uma recusa da necessidade, que dá início ao processo de subjetivação, que acontece apenas quando do confronto com a demanda do Outro. O ser que fala pela necessidade não se conta em sua enunciação. Deste modo, é inócua a conclusão de que seria a necessidade de ter um filho que legitimaria o avanço científico no campo das NTRA. O tratamento da infertilidade pela via da reprodução assistida contempla algo de uma outra ordem; a saber, a demanda.

Perguntamos: a que vem o desejo de filho na mulher infértil que recorre à reprodução assistida?

Há uma relação essencial entre a reprodução sexuada e a aparição da morte... A questão de saber o que liga dois seres no aparecimento da vida não se põe para o sujeito senão a partir do momento em que esteja no simbólico, realizado como homem ou como mulher, mas à medida que um acidente o impeça de aceder até aí. Isso pode ocorrer, outrossim, em virtude dos acidentes biográficos de cada um. (Lacan, 1955-1956, p. 205)

$\mathrm{Na}$ fenda entre o sujeito e o Outro, constitui-se o desejo. O desejo é essencialmente a busca de um lugar, de um momento, de um paraíso perdido, e, portanto, não encontra satisfação. O primeiro desejo está recalcado no inconsciente e retorna substituído por diferentes desejos, como o desejo de filho, por exemplo.

De acordo com Stryckman (2000), o desejo de filho pode vir a ser um produto de diversas operações fantasmáticas, confundindo-se, por exemplo, com o desejo de maternidade, ou com o desejo de simplesmente estar grávida, desejo de parir, desejo de colocar no mundo uma criança, ou ainda produzir o filho do desejo edipiano. Agregamos a estas formulações o desejo de fazer um pai, ou também o desejo de se fazer mulher.

Por meio de nossas pesquisas, vimos o quanto que, na mulher, o desejo de filho está relacionado com a provação de sua sexuação e de sua feminilidade, introduzindo a mulher no real de seu corpo pela via da gravidez. Seguimos pelo que nos diz Lacan (1955-1956), que a posição sexuada está longe de ser pura extravagância da natureza, necessitando de uma ordenação pela palavra para que tudo venha a se regular e a se tornar conhecido. Sabemos que a condição de falasser implica uma posição de desejo que afeta o corpo e o modifica. Pensando o que ocorre na infertilidade da mulher que usa seu corpo como local privilegiado do sintoma, temos como hipótese que se trata de uma realidade psíquica que se realiza, se congela no infértil. Haveria, nestes casos, um estado de alienação ao Outro, do qual o sujeito tenta fazer barreira pela via do corpo. Neste sentido, entende- 
mos que ocorre um esforço inconsciente pela preservação do desejo que se constitui como uma negação da demanda, fazendo barreira e dando limite a um excesso de gozo que resultaria da colagem ao Outro. Conforme as pesquisas de Chatel (1995), estes sujeitos se estruturam por meio de um desarranjo significante, resultando numa impossibilidade de expressão que seja fecunda.

É por meio da denegação, que faz o significante emergir do recalque, que o desejo pode ser apontado, sendo possível, deste modo, realizar uma análise da posição fantasmática do sujeito. Lacan nos ensina que o significante é o que representa o sujeito para outro significante, sendo que assim, a cada vez que o sujeito é representado, deixa para trás de si um significante que foi, de alguma forma ou em algum lugar, posicionado. Deixa igualmente um rastro da posição original do sujeito, não marcado pela transformação que a demanda do Outro exige e a que o circuito pulsional efetua. Em seu sintoma o sujeito se repete, à medida que seu desejo à frente vem do passado, ou seja, sombra do objeto perdido e indestrutível. Por meio da escuta clínica, vemos que o que retorna é o que foi recalcado para permitir a transformação do circuito pulsional. O recalque do objeto da infância é o que permite sua substituição por um objeto polissêmico, no caso de uma metáfora, sendo que o sintoma é um excesso de sentido, uma restrição à polissemia desse novo objeto.

Deste modo, concluímos que aquilo que faz marca não mais se apaga, o que apenas é possível mudar é a significação do significante; ou, como diz Jerusalinsky (2001), “... pode ser recalcada, pode ser retida, desviada, configurada, substituída na sua função, mas não se apaga mais" (p. 28).

É suposto que para ser falante é preciso estar determinado a este desejo Outro. O desejo do falasser ${ }^{1}$ estará necessariamente relacionado ao desejo Outro que o compõe. Poderíamos pensar que sempre que há desejo é porque houve uma identificação ao desejo do Outro, ou seja, que desejo é desejo do desejo do $O u$ tro. No entanto, este desejo, apesar de vir do Outro, é subjetivado à medida que o sujeito está em constituição.

No momento em que o sujeito se constitui, ou seja, no deslocamento do $\mathrm{S}_{1}$ para o $\mathrm{S}_{2}$, há uma sobra desta operação, um resto que definimos como objeto a. Este objeto caído torna-se causa de desejo que situará o sujeito em relação ao seu fantasma. O objeto que constitui o fantasma é constituído por um desejo. Este

1. O "parlêtre" de Lacan. 
objeto original é recalcado, tomando seu lugar objetos equivalentes, como podemos supor, o filho. Fazendo referência à nossa proposta de pesquisa, vamos nos ocupar do que nos aponta Lacan (1964, p. 224-225), no que ele elabora acerca de um efeito psicossomático, ou seja, de que quando não haveria intervalo entre $\mathrm{S}_{1}$ e $\mathrm{S}_{2}$, ou, nas palavras de Lacan: "quando a primeira dupla de significantes se solidifica, se holofraseia".

O avanço das tecnologias biológicas, como, por exemplo, os métodos contraceptivos, dá à mulher a ideia da possibilidade de controle do desejo, o que é sem dúvida um engodo. Suas realizações nas esferas do trabalho e do estudo, bem como no campo financeiro, geralmente servem de critério para que as mulheres adiem os planos de gravidez, marcando datas e fases de vida "ideais" para que tenham seus filhos.

Tal barreira aos projetos de maternidade no "tempo certo" pode funcionar como uma falha na construção narcísica de algumas mulheres. Talvez se possa pensar que a busca pela tecnologia de reprodução assistida tende a corrigir tal falha de um modo por vezes breve, sem tempo para reflexões sobre o próprio desejo. Charles Melman (2003), ao nos falar acerca do progresso tecnológico, coloca em questão a liberdade do sujeito frente aos objetos fantásticos disponíveis na atualidade. Segundo o autor, vivemos num paradoxo, no qual ao mesmo tempo em que nos acreditamos livres para escolhas, como, por exemplo, o tempo e o método de ter filhos, nos encontramos presos em armadilhas narcísicas.

Freud, em "Três ensaios sobre a teoria da sexualidade" (1905), desnaturaliza a relação sexo-sexualidade-reprodução, abrindo caminho para a expressão da libido desvinculada da fecundação. De todo modo, Freud não liberta as psiconeuroses das forças pulsionais de cunho sexual. Ou seja, as formações sintomáticas do inconsciente estão expressamente ligadas à energia da pulsão sexual, que dá forma aos sintomas.

As autoras Silvia Cincunegui, Yolanda Kleiner e Póla Woscoboinik (2004) apresentam hipóteses ao que estaria relacionado à dita "infertilidade enigmática", ou seja, àquele diagnóstico que é conferido às mulheres que não apresentam diagnóstico de causa orgânica para sua infertilidade, ou, citando a nomenclatura médica, as ESCA (Esterilidades Sem Causa Aparente). Segundo estas autoras, haveria uma inibição da função reprodutora que se constitui como um sintoma com especificidade e sentido, que não guarda relação necessária com uma estrutura psíquica determinada. O sintoma fica especificado no que se refere à escolha dos órgãos e suas funções. É um sintoma no corpo, que concebemos como corpo 
erógeno. Abarca sentido, que irá sendo construído sobre as marcas de episódios potencialmente traumáticos da história da paciente ou de gerações anteriores, que encontram relação com a procriação.

Embora Marina Ribeiro (2004) aborde em seu livro as controvérsias contemporâneas de um diagnóstico de infertilidade psicogênica, ela compreende, de acordo com sua pesquisa, que "esta é consequência de conflitos inconscientes ligados à sexualidade, afetos ambivalentes em relação à maternidade, conflitos edípicos não elaborados e conflitos ligados à identidade de gênero", e como menciona em outra passagem, "como repúdio inconsciente à feminilidade e à maternidade" (p. 73-74).

Remetemo-nos novamente aos fenômenos psicossomáticos e às conversões. $\mathrm{Na}$ conversão, resgata-se o sentido que pode portar o sintoma, como expresso no pensamento freudiano articulado no texto "Três ensaios sobre a teoria da sexualidade". No caso das afecções psicossomáticas, vemos tratar-se de um enfoque que evoca a dinâmica das neuroses atuais, em que a descarga da angústia se dá diretamente no corpo. Os fenômenos psicossomáticos se apresentam tais como uma conversão histérica, contudo, apontam uma lesão ao corpo e pertencem ao registro do Real, podendo estar fora da esfera das construções neuróticas. Auxilia-nos Lacan (1954-1955):

Em qualquer relação narcísica, o eu é com efeito o outro, e o outro é o eu. A neurose está sempre enquadrada pela estrutura narcísica. Mas como tal ela está além, num outro plano. Este outro plano, não é o plano da relação ao objeto. (...) Se algo é sugerido pelas reações psicossomáticas como tais, é justamente por elas estarem fora do âmbito das construções neuróticas. Não se trata de uma relação ao objeto. Trata-se de uma relação a algo que está sempre no limite de nossas elaborações conceituais, em que se pensa sempre, em que se fala por vezes, e que propriamente falando não podemos apreender e que, no entanto, está aí, não se esqueçam disto - estou lhes falando do simbólico, do imaginário, mas há também o real. As relações psicossomáticas estão no nível do real. (p. 127)

Ao retirarmos o desejo de filho e a infertilidade do campo do exclusivamente biológico, propomos que a maternidade não é instinto, mas escolha, alicerçada no fantasma. Assim separamos, pelo corte simbólico, a subjetividade da natureza. Ressaltamos as palavras da psicanalista Ana Maria Sigal (2003): “Assim como não se nasce mulher para o inconsciente, não se nasce mãe. Seja através do coito, da fertilização assistida ou da adoção, a mulher alcança sua condição de mãe a partir das inscrições simbólicas que pode realizar" (p. 11). 
Adentramos nas histórias de Marina, Maia, Maira e Mara. Elas têm em comum a vontade de ter um filho consanguíneo. Estão na faixa etária que vai dos trinta aos quarenta anos, e são inférteis. Elas estão agora em tratamento em uma clínica de reprodução humana assistida. Nenhuma delas havia pensado que poderiam conversar sobre seus problemas de fertilidade com uma analista; revelaram. Entretanto, uma vez posta esta possibilidade a cada uma delas, aceitam.

O "continente negro", representado por estas quatro mulheres, fala de um vazio, de uma falta crucial, quando mencionam a ausência de um filho nas suas vidas. Embora nos diga Lacan (1955-1956), que "o sexo feminino tem uma característica de ausência, de vazio, de buraco, que faz com que pareça ser menos desejável que o sexo masculino no que ele tem de provocante, e com que uma dessimetria essencial apareça" (p. 202); vemos que este vazio que elas apontam está mais para uma falta do ser do que para uma falta no ter.

Segundo a psicanalista Sílvia Tubert (1996), a reivindicação de um filho a qualquer preço pode estar correspondendo a uma carência de metáfora que diga à mulher quem ela é, ou melhor, que falta um significante que a enlace no real, simbólico e imaginário. Neste sentido, apenas a maternidade no real pode fazer algumas mulheres ascenderem como sujeito sexuado no feminino, tal como uma restituição de sua posição subjetiva. Muito ao contrário de uma ascensão à maternidade pela via do simbólico. A ciência e o médico, nestes casos, encarnam o Nome-do-Pai e a produção no real do corpo, fazendo operar um significante que garanta sua estrutura como sujeito. Aqui a criança é o falo.

A aplicação das novas tecnologias médicas no corpo da mulher coloca radicalmente em evidência a verdade da divisão subjetiva: ou seja, o fato de que o ser humano é habitado por um saber (inconsciente) que o pensamento consciente ignora e cujos efeitos não podem ser evitados por nenhuma decisão racional. (Mieli, 1997, p. 6)

Tubert (1996) nos assinala o quanto o corpo das mulheres em tratamento passa a ser tomado como obstáculo ao querer consciente. Corpo que passa a ser falado por meio das palavras da medicina: "Meu marido tem espermatozoides com baixa mobilidade, já tiveram médicos que deram $0 \%$ de chance de ele ser pai, aí fizemos novos exames e teve um médico que disse que ele poderia sim ser pai quando quisesse, só tinha que fazer o tratamento" (Maia, trinta anos). Aqui vemos que o corpo é tomado na concretude do real e excluído da ordenação do desejo.

As mulheres falam repetidamente dos diferentes tratamentos e da resposta de seus corpos, como buscando explicar um enigma; quase que procurando, atra- 
vés da repetição, o sentido de algo impossível de entender, obcecadas por localizar no corpo a realidade do impossível. (p. 25)

Diz Marina, 37 anos: "Tenho tentado engravidar há uns dez anos. Foram tentativas, desistências, tentativas, desistências... Tem um probleminha meu e um probleminha dele também, minhas trompas não são muito boas. A gente procurava médicos, fazia exames, tratava um pouco, mas nunca alcançava o resultado esperado e sempre acabava desistindo por uma razão ou outra. Lá no interior não tem clínicas especializadas com quem (sic) a gente pudesse contar." $\mathrm{O}$ casal não para de repetir o fracasso de seus corpos, alternando-se a cada tentativa como responsável pela não vinda dos filhos. A questão que nos colocamos é: por que acabam sempre desistindo? Seus corpos já lhes dizem não desde o princípio.

Mara, 31 anos, casada. Marido, 33 anos. Têm tentado engravidar há cinco anos, estão juntos há 14. "Surgiu a vontade de ter filhos quando atrasou a menstruação e todo mundo ficou falando e tal, eu nem tava casada, tava noiva dele ainda (sic). Comecei a enjoar e fui no médico e falei o que tava sentindo e ele me disse que eu estava grávida. Não fiz exames nada, simplesmente ele me disse que eu estava grávida; e aquilo alimentou minha ilusão. Comecei a assimilar aquilo que eu não queria e depois de duas semanas desceu a menstruação. Aí eu fui no médico e ele me disse: não tu não está grávida, não tem vestígio nenhum de gravidez. Aí passou mil coisas na minha cabeça e aí eu quis. A gente então casou e ficamos tentando, tentando e nada. Me viraram do avesso e viram que eu não tinha nada; e aí fomos ver se era com ele, até que constatou que era ele o problema. Oligospermia. Eu comecei a querer, querer, querer. Quando ele soube que o problema era com ele, ele sofreu muito e se sentiu o pior homem dos homens... Vamos fazer o possível, vamos lutar até a última, até a última. Tem coisa que é só pra um médico realmente, não adianta rezar. Mesmo sendo ele o problema sou eu que tenho que tomar injeção, fazer os exames, tomar a medicação, coisas da medicina que a gente não entende, né? Eu queria que fosse normal e não foi, e aí eu pensei, então vai ser.. O filho é o que falta pra completar minha felicidade. Agora as minhas cachorrinhas são tudo pra mim, ele me deu quando eu soube que não podia ter um filho."

Percebemos o quanto a demanda de filho, na narrativa de Mara, remete a alguma outra coisa que não o filho propriamente dito. Engravidada pelo médico através do enunciado: "Tu está grávida", Mara experimenta uma outra forma de ser falada. Por meio da possível maternidade encontra outro lugar em sua família e passa a querer o que anteriormente não queria... Eis nossa questão, queria 
ou não? À medida que quer ter um filho, Mara reduz seu marido ao pior dos homens, aquele a quem ela passa a ter compaixão e eleva mais uma vez a própria virtude.

Maíra, trinta anos. Marido, 28 anos, cinco anos de casados. Do lar. "Estou me dedicando ao tratamento. Sempre quis fazer uma faculdade, mas em primeiro lugar eu estou me dedicando à maternidade. Eu cuidei dos meus irmãos (dez), eu sempre tive a maternidade comigo. Problemas nos ovários; removi um cisto. Fiz todos os exames um ano depois de "tentante" (sic). Não aparecia nada, mas eu não conseguia. Por parte da minha família tem muita cobrança. Brincadeirinhas sobre meu marido, que não sabia fazer, essas coisas, que deve acontecer com todo mundo que é "tentante". Já pensei em adoção, tem um filho da minha irmã que é cheia de problemas, mas meu marido nunca quis. Ele tem medo (adoção), tem medo do inesperado, medo de não gostar. Eu tenho amor pra todo mundo. ESCA. Não tem nada que diga: é por isto. Eu tô preparada pra tudo, eu tô muito confiante, eu tô confiante até o final, que vai dar certo! (Chora) eu tô triste, né?(sic) Eu sou muito emotiva, choro por tudo, até vendo filme. Falamos pra bem poucas pessoas. Minha mãe é complicada, é separada do meu pai não sabe, ela é tão distante, ela deixou a gente assim, quando a gente era pequena a gente teve contato mas muito pequeno, ela só vai saber se der certo e não precisa nem saber por que meio. A minha sogra está torcendo longe, sempre longe. Eu estou muito ansiosa, não vejo a hora de acabar. / (Acabar? - perguntamos) / Acabar o tratamento. A cada menstruação era um luto. Por que eu? Sendo que minha família é fértil até demais, né? Eu acho que as crianças trazem alegria. Eu penso no bom e no ruim, não penso só no lado bom, de ver aquela barriga, tem o lado ruim, noites mal-dormidas... mas a gente está se preparando psicologicamente pra isso também. Sempre que eu sonhava aparecia alguém grávida na minha família, mas nunca era eu. Minhas irmãs já têm medo quando eu sonho."

Chama-nos a atenção o significante escolhido por Maíra para dar conta da infertilidade do casal. No caso de Maíra, o qual nos será explicitado, a infertilidade habita ambos os corpos "tentantes". Vemos que o que os coloca em movimento é o fato de estar para sempre tentando engravidar, algo que para Maíra não é possível, pois ocuparia o lugar da mãe junto ao pai, novamente. Mãe dos filhos de sua mãe, Maíra deixa seu mundo girar ao redor da maternidade. Seu amor para todo mundo desconhece os limites que seu corpo lhe impõe. Talvez seu corpo esteja fazendo uma barreira ao desejo inconsciente de incesto, talvez por isso tenha 
que permanecer calada frente à sua mãe. Esta não pode saber de onde vêm os filhos de Maíra. Até suas irmãs engravidam, numa família fértil até demais, afinal foram de dez irmãos que ela se ocupou ao longo de sua vida. Lembramos que Eva, a mãe de todo o ser vivo, também tinha uma proibição a qual não foi acatada. Eva tinha toda a liberdade, exceto liberdade sobre o que se referia a sua vida sexual.

Marina (37 anos) nos relata: "Eu não consigo conversar com a família sobre isso, não dão força pro tratamento, logo de cara já me dizem, por que vocês não adotam? Se eu adotar, ele vai ser tratado diferente. Fico inferiorizada como mulher. O filho é tudo que eu quero, eu deixaria de fazer qualquer coisa para ter. Eu só consigo falar disso (infertilidade) com meu marido e mesmo assim a gente procura não falar". A partir do relato de Marina, pensamos que se ela adotar, é ela - enquanto mãe - que será tratada diferente das outras mulheres da família. Embora os discursos sobre a maternidade sejam variáveis ao longo do tempo, vemos aqui diversas configurações de uma produção discursiva que diz que a mulher necessita da maternidade para estar situada em seu mundo, em sua família. Estes discursos sobre a maternidade são responsáveis pelos laços possíveis destas mulheres em seu meio social, comprometendo-as enquanto sujeitos que formulam este enunciado: quero ter filhos. No caso de Marina, o desejo de maternidade está mais em evidência do que o desejo de ter um filho propriamente dito. Ou seja, a possibilidade de ser se evidencia em relação à possibilidade de ter. Deste modo, podemos pressupor que a busca pela plenitude narcísica, destacada pela prevalência da dimensão imaginária, se prioriza em detrimento de uma escolha feita a partir do Ideal do Eu, ou seja, a partir de uma resolução da configuração edípica da menina que, identificada com a mãe, passaria a demandar um filho. Neste caso a identificação é através do plano primário, no qual ainda não há diferenciações possíveis, ficando reduzido a uma relação a - a'.

No caso de Maia (trinta anos) o desejo de filho encontra-se articulado em uma dimensão simbólica, na qual se pressupõe um reconhecimento da castração. Ela nos relata: "Há três anos tenho tentado engravidar. O problema aparece pra nós dois, eu tive endometriose e ele espermatozoides com baixa mobilidade. Ele quis acabar, mas eu segurei não é porque ele não pode ter filhos que vou acabar. A medicina está aí, a evolução dela é grande. Eu procuro ir pelo lado positivo. Agora é o momento certo, a gente já terminou a faculdade, temos emprego estável". Percebemos que para Maia, o filho tem um lugar em sua vida que não é todo, há espaço para outras realizações, sendo que o fato de não poder engra- 
vidar durante três anos não a impede de prosseguir com seu trabalho e relacionamento amoroso. Talvez possamos refletir quanto à tentativa de controle de sua vida, controle que encontra escape quando não consegue engravidar no tempo previsto, mas que logo retorna ao controle médico.

A evidência de que determinações inconscientes atuam diretamente na ordem sexual, na qual subjazem as relações de identificação, convoca os psicanalistas a se preocuparem acerca das formas contemporâneas de laço social que refletem nas demandas de nosso tempo e retornam como efeitos na prática clínica. É por meio da análise do impedimento de ter um filho, que podemos questionar sobre este desejo, que talvez permanecesse oculto caso pudesse ser sempre realizado. Roudinesco (2003) conclui que à medida que as mulheres passaram a dominar os processos de procriação, foram acusadas de tentar suprimir ainda mais as diferenças sexuais, atentando contra a essência masculina. Dissociar feminilidade de maternidade dificulta as possibilidades de classificação das mulheres como todas em um só conjunto. Se algumas não são mães, perguntamos - não sem ironia o que são, as mulheres?

Concluímos, de todo modo, que a reprodução assistida, outrora chamada artificial, não é senão, mais um instrumento a serviço da pulsão humana, tencionando energia capaz de abrir caminho para a vida ou fechá-la para a morte. A impossibilidade destas mulheres frente à adoção, ou seja, uma solução substitutiva, sugere-nos a reflexão de duas questões: ou a única possibilidade de inscrição simbólica se dará pela via do real do corpo, engendrando em si seu filho e, só assim, tornando-se mãe, ou, pela insatisfação da demanda, reinaugurando um lugar de sujeito desejante.

\section{Referências}

AtLan, H. L'utérus artificiel. Paris: Seuil, 2005.

Aulagnier, P. Que desejo, por que filho? Revista Psicanálise e Universidade, São Paulo, n. 21, p.,11-16, set. 2004.

Imago, 1979.

. A violência da interpretação: do pictograma ao enunciado. Rio de Janeiro:

Chatel, M-M. Mal-estar na procriação: as mulheres e a medicina da reprodução. Rio de Janeiro: Campo Matêmico, 1995. 
CORRÊA, M.V. Ética e reprodução assistida: a medicalização do desejo de filhos. Bioética, v. 9, n. 2, p. 71-82, 2001.

. Novas tecnologias reprodutivas: doação de óvulos. O que pode ser novo neste campo? Cadernos de Saúde Pública, v. 16, n. 3, p. 863-870, 2000.

. A tecnologia a serviço de um sonho: um estudo sobre a reprodução assistida no Brasil. 1997. Tese. (Doutorado em Medicina Social). Universidade do Estado do Rio de Janeiro.

Freud, S. (1905). Três ensaios sobre a teoria da sexualidade. In: Edição Standard Brasileira das Obras Psicológicas Completas de Sigmund Freud. Rio de Janeiro: Imago, 1996. V. VII.

. (1913a). O tema dos três escrínios. In: Edição Standard Brasileira das Obras Psicológicas Completas de Sigmund Freud. Rio de Janeiro: Imago, 1996. V. XII. . (1913b). Uma contribuição ao problema da escolha da neurose. In: Edição Standard Brasileira das Obras Psicológicas Completas de Sigmund Freud. Rio de Janeiro: Imago, 1996. V. XII.

. (1917[1915]). Luto e melancolia. In: Edição Standard Brasileira das Obras Psicológicas Completas de Sigmund Freud. Rio de Janeiro: Imago, 1996. V. XIV. . (1917). As transformações do instinto exemplificadas no erotismo anal. In: Edição Standard Brasileira das Obras Psicológicas Completas de Sigmund Freud. Rio de Janeiro: Imago, 1996. V. XVII.

. (1921). Psicologia de grupo e a análise do ego. In: Edição Standard Brasileira das Obras Psicológicas Completas de Sigmund Freud. Rio de Janeiro: Imago, 1996. V. XVIII.

. (1926). A questão da análise leiga. In: Edição Standard Brasileira das Obras Psicológicas Completas de Sigmund Freud. Rio de Janeiro: Imago, 1996. V. XX. . (1930[1929]). O mal-estar na civilização. In: Edição Standard Brasileira das Obras Psicológicas Completas de Sigmund Freud. Rio de Janeiro: Imago, 1996. V. XXI.

. (1931). Sexualidade feminina. In: Edição Standard Brasileira das Obras Psicológicas Completas de Sigmund Freud. Rio de Janeiro: Imago, 1996. V. XXI. . (1933[1932]). A feminilidade. In: Edição Standard Brasileira das Obras Psicológicas Completas de Sigmund Freud. Rio de Janeiro: Imago, 1996. V. XXII. IACuB, M. Empire du ventre - pour une autre histoire de la maternité. Paris: Fayard, 2004. 
. L'utopie de l'utérus articiel. Le nouvel Observateur - Hors série - Les Utopies d'aujour'hui. Paris, jul./ago. 2005.

JARDIM, L.L. O risco familiar de câncer de mama: a psicanálise diante da pesquisa genética. 1998. Dissertação. (Mestrado em Psicologia). Pontifícia Universidade Católica do Rio Grande do Sul.

Jerusalinsky, A. Seminários I. São Paulo: Instituto de Psicologia da USP, 2001. KeHL, M.R. O sintoma no laço social contemporâneo. Texto mimeografado e não publicado. s/data.

. Deslocamentos do feminino: a mulher freudiana na passagem para a modernidade. Rio de Janeiro: Imago, 1998.

. O sexo, a morte, a mãe e o mal. In: Nestrovsky, A.; Seligmann-Silva, M.

Catástrofe e representação. São Paulo: Escuta, 2000.

LACAN, J. (1938). Os complexos familiares na formação do indivíduo: ensaio de análise de uma função em psicologia. Rio de Janeiro: Jorge Zahar, 2002.

. (1954-1955). O seminário. Livro 2. O eu na teoria de Freud e na técnica da psicanálise. Rio de Janeiro: Jorge Zahar, 1985.

. (1955-1956). O seminário. Livro 3. As psicoses. Rio de Janeiro: Jorge Zahar, 1988.

. (1956-1957). O seminário. Livro 4. A relação de objeto. Rio de Janeiro: Jorge Zahar, 1995.

. (1957-1958). O seminário. Livro 5. As formações do inconsciente. Rio de Janeiro: Jorge Zahar, 1999.

. (1958-1959). O seminário. Livro 6. O desejo e sua interpretação. Porto Alegre: Publicação não comercial de circulação interna da Associação Psicanalítica de Porto Alegre, 2002.

. (1959-1960). O seminário. Livro 7. A ética da psicanálise. Rio de Janeiro:

Jorge Zahar, 1997. 2005.

. (1962-1963). O seminário. Livro 10. A angústia. Rio de Janeiro: Jorge Zahar,

. (1964). O seminário. Livro 11. Os quatro conceitos fundamentais da psicanálise. Rio de Janeiro: Jorge Zahar, 1998.

. (1969-1970). O seminário. Livro 17. O avesso da psicanálise. Rio de Janeiro:

Jorge Zahar, 1992. 
. (1953). Função e campo da fala e da linguagem em psicanálise. In: Escritos. Rio de Janeiro: Jorge Zahar, 1998. p. 238-324. p. $692-703$.

. (1958). A função do falo. In: Escritos. Rio de Janeiro: Jorge Zahar, 1998.

. (1960). Subversão do sujeito e a dialética do desejo no inconsciente freudiano. In: Escritos. Rio de Janeiro: Jorge Zahar, 1998. p. 807-842.

. (1965-1966). A ciência e a verdade. In: Escritos. Rio de Janeiro: Jorge Zahar, 1998.

. (1966). Psicanálise e medicina. Texto não disponível em edições comerciais.

. (1975-1976). O seminário. Livro 23. O sinthoma. Rio de Janeiro: Jorge Zahar, 2007.

Mieli, P. Notes sur les implications actuelles de la reproduction assistée. Revue Internationale de Psychanalyse, Paris, 1997.

Poli, M.C.C. Perversão da cultura. Neurose do laço social. Ágora, Rio de Janeiro, v. VII, n. 1, p. 39-54, jan/jul. 2004.

. Problematizando a bioética. Correio da APPOA, Porto Alegre, n. 143, p. 17-20, jan.2006. . Feminino/masculino. Rio de Janeiro: Jorge Zahar, 2007.

Ribeiro, M. Infertilidade e reprodução assistida. São Paulo: Casa do Psicólogo, 2004.

Roudinesco, E. A família em desordem. Rio de Janeiro: Jorge Zahar, 2003.

Sigal, A.M. A psicanálise, o feminino e sua relação com as novas técnicas de fertilização assistida. Estados Gerais da Psicanálise: Segundo Encontro Mundial, Rio de Janeiro, 2003.

SouZa, M.C.B.; Moura, M.D.; Grynspan, D. Vivências em tempo de reprodução assistida: o dito e o não-dito. Rio de Janeiro: Revinter, 2008.

Strickman, N. O desejo de filho no homem e na mulher. Psicanálise e Clínica de Bebês, Curitiba, ano IV, n. 4, p. 91-108, dez. 2000.

ToRT, M. O desejo frio. Procriação artificial e crise dos referenciais simbólicos. Rio de Janeiro: Civilização Brasileira, 2001.

TUBERT, S. Mulheres sem sombra: maternidade e novas tecnologias reprodutivas. Rio de Janeiro: Rosa dos Tempos, 1996. 


\section{Resumos}

(Reproducción asistida: las encrucijadas del deseo)

La infertilidad es para muchas mujeres generadora de sufrimiento psíquico, una vez que la reproducción humana busca la perpetuación del ser. Este artículo haz una discusión de las llamadas Nuevas Tecnologías Reproductivas y estudia los efectos que la infertilidad tiene en la psique y en la condición subjetiva de los sujetos del deseo. El artículo busca disociar la demanda consciente de tener un hijo del deseo inconsciente que opera en la producción subjetiva, haciendo síntoma. Apunta la diferencia entre el deseo de tener un hijo e el deseo de maternidad y sus implicaciones sobre la articulación de los impulsos.

Palabras claves: Infertilidad, reproducción humana asistida, feminidad, deseo

(La reproduction assistée: les impasses du désir)

Pour beaucoup de femmes, l'infertilité est cause de souffrance psychique, la reproduction humaine représentant une recherche de la perpétuation de l'être humain. Cet article porte sur une discussion autour de ce qu'il est convenu d'appeler les Nouvelles Technologies de Reproduction et étudie les effets de l'infertilité sur le psychisme et sur la condition subjective des sujets de désir. Nous essayons de dissocier la demande consciente d'avoir un enfant du désir inconscient qui opère dans la production subjective et qui provoque le symptôme. Nous mettons l'accent sur la différence entre le désir d'avoir un enfant et le désir de maternité, de même que sur leurs implications dans l'articulation des pulsions.

Mots clés: Infertilité, reproduction humaine assistée, féminité, désir

(Assisted reproduction: the impasses of desire)

Infertility is the cause of psychic suffering for many women, since human reproduction aims at the perpetuation of living beings. This article discusses the socalled new reproductive technologies and studies the impacts that infertility has on the psychism and on the condition of the subject. It seeks to dissociate the conscious demand of having a child from an unconscious desire that may operate in the subject's production, thus causing symptoms. It also questions the difference between that desire to have a child and the desire for motherhood and its implications in articulating the drives.

Key words: Infertility, assisted human reproduction, femininity, desire 
Citação/Citation: Lanıus, M; SouZA, E.L.A. Reprodução artificial: os impasses do desejo. Revista Latinoamericana de Psicopatologia Fundamental, São Paulo, v. 13, n. 1, p. 53-70, mar. 2010.

Editor do artigo/Editor: Prof. Dr. Manoel Tosta Berlinck

Recebido/Received: 9.1.2009/1.9.2009

Aceito/Accepted: 4.2.2009/2.4.2009

Copyright: (๑ 2010 Associação Universitária de Pesquisa em Psicopatologia Fundamental/University Association for Research in Fundamental Psychopathology. Este é um artigo de livre acesso, que permite uso irrestrito, distribuição re reprodução em qualquer meio, desde que o autor e a fonte sejam citados/ This is an open-acess article, which permits unrestricted use, distribution, and reproduction in any madium, provided the original author and source are credited

Financiamento: Os autores declaram não ter sido financiados ou apoiados/ The authors have no support of funding to report.

Conflito de interesses: Os autores declaram que não há conflito de interesse/ The authors declares that they have no conflict of interest.

\section{Manuela Lanius}

Psicanalista; mestre em Psicologia Social e Institucional pela Universidade Federal do Rio Grande do Sul - UFRGS (Porto Alegre, RS, Brasil); integrante do LAPPAP - Laboratório de Pesquisa em Psicanálise, Arte e Política; membro da Associação Psicanalítica de Porto Alegre (Porto Alegre, RS, Brasil).

Rua Barão de Ubá, 511/601

90450-090 Porto Alegre, RS, Brasil

e-mail: manulanius@terra.com.br

\section{Edson Luiz André de Sousa}

Psicanalista; professor do Programa de Pós-Graduação em Psicologia Social e Programa de Pós-Graduação em Artes Visuais da Universidade Federal do Rio Grande do Sul - UFRGS (Porto Alegre, RS, Brasil); professor do Departamento de Psicanálise e Psicopatologia do Instituto de Psicologia - Universidade Federal do Rio Grande do Sul - UFRGS (Porto Alegre, RS, Brasil); doutor em Psicanálise e Psicopatologia pela Universidade de Paris VII; pesquisador do CNPq; coordena junto com Maria Cristina Poli o LAPPAP (Laboratório de Pesquisa em Psicanálise, Arte e Política); membro da Associação Universitária de Pesquisa em Psicopatologia Fundamental (São Paulo, SP, Brasil); membro da Society of 
Utopian Studies; analista membro da Associação Psicanalítica de Porto Alegre (Porto Alegre, RS, Brasil); professor visitante na Deakin Universtiy (Melbourne, 2006); professor visitante no Instituto de Estudos Críticos (Cidade do México, 2007); pesquisador colaborador do grupo Pandora - Université de Paris VII (Paris, França); autor dos livros Freud: ciência, arte e política junto com Paulo Endo (Porto Alegre: LPM, 2009), Uma invenção da Utopia (São Paulo: Lumme Editor, 2007), Freud (São Paulo: Editora Abril, 2005).

Rua Fernandes Vieira, 474/32

90035-090 Porto Alegre, RS, Brasil

e-mail: edsonlasousa@uol.com.br 